\title{
REVIEW \\ Counseling patients about sexual health when considering post-prostatectomy radiation treatment
}

\author{
D Wittmann ${ }^{1,2}$, JE Montie ${ }^{1}$, DA Hamstra ${ }^{3}$, H Sandler $^{4}$ and DP Wood Jr $^{1}$ \\ ${ }^{1}$ Department of Urology, University of Michigan, Ann Arbor, MI, USA; ${ }^{2}$ Department of Social Work, center for sexual \\ health, University of Michigan, Ann Arbor, MI, USA; ${ }^{3}$ Department of Radiation Oncology, University of Michigan, Ann \\ Arbor, MI, USA and ${ }^{4}$ Department of Radiation Oncology, Cedars-Sinai Medical Center, Samuel Oschin Comprehensive \\ Cancer Institute, Los Angeles, CA, USA
}

\begin{abstract}
Prostate cancer is the second most frequently diagnosed cancer in men in the United States. Many men with clinically localized prostate cancer survive for 15 years or more. Although early detection and successful definitive treatments are increasingly common, a debate regarding how aggressively to treat prostate cancer is ongoing because of the effect of aggressive treatment on the quality of life, including sexual functioning. We examined current research on the effect of post-prostatectomy radiation treatment on sexual functioning, and suggest a way in which patient desired outcomes might be taken into consideration while making decisions with regard to the timing of radiation therapy after prostatectomy.
\end{abstract}

International Journal of Impotence Research (2009) 21, 275-284; doi:10.1038/ijir.2009.32; published online 16 July 2009

Keywords: prostate cancer; post-prostatectomy; radiation; sexual functioning

\section{Introduction}

Prostate cancer is the second most frequently diagnosed cancer in men in the United States. Many men with clinically localized prostate cancer survive for 15 years or more. Although early detection and successful definitive treatments are becoming increasingly common, a debate regarding how aggressively to treat prostate cancer is ongoing. When surgical treatment is unable to remove all evidence of tumor (margins are not clear, there is an extraprostatic extension, seminal vesicles are involved), radiation therapy may be considered to decrease the risk of recurrence. Both initial radical prostatectomy and radiation therapy have significant effects on sexual functioning, thus decreasing patients' quality of life (QOL). We examined current research on the effect of post-prostatectomy radiation treatment on sexual functioning, and suggest a

Correspondence: D Wittmann, Department of Urology, Taubman Health Center, University of Michigan, 1500 E. Medical Driv, Ann Arbor, MI 48109-5330, USA.

E-mail: dwittman@med.umich.edu

Received 5 May 2009; revised 8 June 2009; accepted 12 June 2009; published online 16 July 2009 way in which patient desired outcomes might be taken into consideration while making decisions with regard to the timing of radiation therapy after prostatectomy.

\section{Materials and methods}

PubMed was searched for studies on radiation therapy after prostatectomy, using the following keywords: prostate cancer, adjuvant radiation therapy after prostatectomy, salvage radiation therapy after prostatectomy, QOL with post-prostatectomy radiation therapy and sexual functioning with post-prostatectomy radiation therapy. The search included linked studies and yielded 20 articles and two comments. The goal of this review is to summarize what is currently known about the sexual sequelae of post-prostatectomy radiation treatment to guide discussions with patients who may be candidates for this intervention.

Institutional review board approval was not required. The authors attest that they have no financial and personal relationships among themselves and with others that might bias their work. 


\section{Results}

\section{The timing of post-prostatectomy radiation} treatment

Current research on post-prostatectomy radiation therapy explicitly evaluates its effect on survival. However, treatment need and effectiveness must be weighed against the possibility of overtreatment and long-term effects on the QOL. ${ }^{2,3}$ Adjuvant radiation therapy is typically delivered to men with a high risk for recurrence, roughly 12-16 weeks after prostatectomy, even without any evidence of relapse. It is, by definition, more aggressive, because it delivers radiation to a proportion of men who would never have required radiation therapy. It emphasizes disease control by being delivered when tumor volume is at its lowest, but may affect erectile functioning. The timing of adjuvant radiation therapy often reflects the desire to protect urinary functioning, which can resolve within months of prostatectomy. Erectile recovery after nerve-sparing surgery takes 18 months to 2 years, ${ }^{4}$ which puts erectile functioning at greater risk of permanent damage. Adjuvant therapy (chemotherapy and/or radiation) is commonly successful in the treatment of breast, lung, colorectal and other malignancies. Given the fact that, in prostate cancer, serum biomarker-prostate-specific antigen (PSA)—can herald clinical relapse $\sim 5$ years in advance, the merit of adjuvant therapy continues to be studied. Salvage radiation therapy is delivered when patients have evidence of a biochemical relapse with PSA or a clinical relapse with evidence of local recurrence. It can be seen as reactive to a relapse, at least initially. It has the advantage of allowing the patient to heal sexually after surgery and of avoiding unnecessary additional treatment. However, the protective value of salvage radiation therapy must be balanced against a potential decline in the chance of prostate cancer cure if radiation is deferred until a time when its efficacy decreases. Factors that might predict the success of salvage radiation are the following: (1) a Gleason's score of $<8$; (2) a preradiation therapy PSA of $<2.0 \mathrm{ng} \mathrm{ml}^{-1}$; (3) positive surgical margins; (4) pretreatment PSA doubling time of $>10$ months; and (5) a lack of invasion of seminal vesicles. ${ }^{5}$ Patients with favorable characteristics for all five features had a $>70 \%$ chance of biochemical control 4 years after salvage radiation therapy. ${ }^{6}$

The effectiveness of adjuvant radiation therapy in preventing PSA relapse and metastasis has been described in several retrospective $e^{7,8,9}$ and prospective $\mathrm{e}^{10,11}$ studies, with some studies also attempting to determine factors that would predispose patients to a positive response to adjuvant therapy. ${ }^{12-14}$ The long-term follow-up of the Southwest Oncology Group adjuvant radiation therapy trial (SWOG $8794 /$ RTOG 9019 ) with 12 -year data ${ }^{15}$ provides the

strongest support for the effectiveness of adjuvant radiation therapy. The study cohort included 425 eligible men with pathological pT3N0M0 prostate cancer who had undergone radical prostatectomy and were found to have high-risk features: A total of 211 were randomized into an observation group, whereas 214 underwent adjuvant radiation therapy within 10 working days of randomization. At a median follow-up of over 12 years, 54\% of the observation group participants died or had metastatic disease, but only $43 \%$ of the adjuvant radiation therapy participants reached the same end point. Median metastasis free survival was 12.9 and 14.7 years for the observation and treatment groups, respectively. Similarly, a study reviewing biochemical progression-free survival in the European Organization for the Research and Treatment of Cancer (EORTC/22911) found in a 5-year follow-up of 1005 patients with clinical pT3N0M0, randomly assigned to immediate postoperative radiation therapy $(\mathrm{N}=502)$ and observation $(\mathrm{N}=503)$, that adjuvant radiation therapy led to a significantly improved likelihood of a biochemical relapse-free survival. ${ }^{16}$ Given the modest duration of this study's follow-up, the long-term risk of metastatic disease is not yet known.

The debate with regard to adjuvant vs salvage radiation continues on the basis of criticisms of the SWOG study design, as well as on the utility of comparing a cohort that was treated 20 years ago to present day patients. ${ }^{17,18}$ Although both the SWOG and EORTC studies showed an improvement in study end points, there are methodological issues that compromise an unqualified acceptance of these results, such as enrollment of patients in both arms with detectable PSA after prostatectomy (that is,. already in relapse), plus applying 'early' salvage radiation therapy to only $\sim 20 \%$ of relapsing patients.

A recently published well-controlled German study (Arbeitsgemeinschaft Radiologische Onkologie und Urologische Onkologie (ARO96-02/AUO AP09/95) ${ }^{19}$ ), which compared adjuvant radiation therapy with observation, supports the conclusions drawn by the SWOG 8794/RTOG 9019 and EORTC/ 22911 studies. The researchers found a $20 \%$ reduction of risk of biochemical progression and local relapse in the adjuvant arm.

A new study in the United Kingdom and Canada (Radiotherapy and Androgen Deprivation In Combination After Local Surgery (RADICALS) ${ }^{17}$ ) is attempting to define more clearly postoperative freedom from disease (undetectable PSA) and criteria for timing salvage treatment. Patients with high-risk pathological features are randomized to receive adjuvant radiation therapy within 2 months. The observation arm will proceed to salvage radiation therapy as soon as patients' PSA rises above $0.1 \mathrm{ng} \mathrm{ml}^{-1}$. Men may be randomized additionally to an adjuvant 6-month androgen-deprivation therapy. 
The results of these studies are compelling. It is important to allow patients to know about them while making treatment decisions. The benefit of adjuvant therapy is becoming clear but it is not yet a standard of care: overtreatment is a concern and salvage therapy has been insufficiently well studied. $^{20}$ A full review of the effect of the timing of post-prostatectomy radiation therapy on survival is beyond the scope of this paper. We have tried to touch on this discussion to provide a context for the consideration of decisions regarding sexual recovery.

\section{The effect of post-operative radiation therapy on} sexual functioning

Although the precise estimations of erectile dysfunction (ED) secondary to prostate cancer surgery vary from study to study, more than $50 \%$ of men suffer from it and find it upsetting. Studies by Penson, ${ }^{21}$ Schover, ${ }^{22}$ Miller ${ }^{4}$ and Sanda $^{23}$ and collaborators have described both the magnitude of the problem and patients' reactions to this sexual dysfunction.

Radiation therapy also has an effect on ED. The decline is gradual, reaches a nadir at $\sim 18-24$ months $^{24,25}$ and is stable thereafter. It has been proposed that radiation may have an impact on vascular structures leading into and within the penis and that radiation damage to these may mediate the decline in erectile function. The exact physical structures involved with radiation-associated ED have not been elucidated and continue to be studied. ${ }^{26}$ There is some evidence that lower doses of radiation ( $<60-70 \mathrm{~Gy}$ ) given in the adjuvant or salvage setting may be less damaging. ${ }^{26,27}$ However, as primary radiation therapy contributes to $\mathrm{ED}$, it is possible that initiating radiation before post-prostatectomy healing is complete may compound men's sexual difficulties.

Research on the sexual side effects of combined surgical and radiation treatment is only beginning to emerge and results are equivocal and incomplete (Table 1). Hu et al. ${ }^{28}$ reported a significantly worse sexual functioning in men after post-operative salvage radiation than after prostatectomy alone. However, this was not a randomized study and risk factors and treatments were not equally allocated between those treated with surgery only and those who received both surgery and radiation therapy. Patients who underwent post-prostatectomy radiation had a significantly higher likelihood of having a pathologically high-risk disease (26 vs $12 \%$, $P<0.01)$ and a trend toward a lower use of nervesparing radical prostatectomy ( 57 vs $68 \%, P<0.06$ ). As a result, it is possible that the lower sexual function scores were in part related to differences in disease extent, surgical technique and use of hormonal therapy. A prospective study by Formenti et al. ${ }^{29}$ reported a survey of 255 patients 3 years after radical prostatectomy, in which 94 (37\%) received 45-54 Gy adjuvant postoperative radiation therapy. They found no difference between the adjuvant and observation groups in their ability to maintain erectile functioning. Although these results are encouraging, current radiation treatment is delivered to a higher total radiation dose. Therefore, these results may not be applicable to current clinical practice. ${ }^{30}$

Moinpour et al. ${ }^{31}$ reported on prospective assessments of the QOL outcomes for the SWOG 8794 randomized adjuvant radiation therapy trial. In their report on 217 patients, who completed a HealthRelated Quality-of-Life (HRQOL) questionnaire after surgery and before radiation therapy, the researchers found no difference in erectile functioning between 107 patients who underwent radical prostatectomy alone and those who had additional radiation therapy. Both groups had highly prevalent decreased erectile functioning in excess of $90 \%$, which probably does not reflect the current surgical technique. There was no statistical difference between the two groups with regard to ED, although the combined therapy group's erectile functioning was consistently lower. This finding, in combination with the very high rate of ED in both groups, limits the strength of the conclusion that radiation does not detrimentally influence erectile function in men who have preserved erectile function after surgery.

The authors point out that the men report a satisfactory overall QOL at 5 years after treatment, in spite of low sexual functioning and significant urinary frequency symptoms for the combined treatment group. This conclusion contradicts other QOL studies (Wei et al. ${ }^{32}$-4-year follow-up, Sanda et $a .^{23}$-2-year follow-up), which report that men evidence significant bother regarding loss of erectile functioning, thus indicating a less than acceptable QOL. In Sanda's study, partners also report being bothered with regard to men's sexual changes. Wei's and Sanda's results are supported by Hedestig, ${ }^{33}$ Bokhour, ${ }^{34}$ Katz $^{35}$ and colleagues, who show that men feel demoralized and emasculated by loss of sexual functioning after prostate cancer treatment. If, as suggested by Moinpour et al., after 5 years, men report an overall high-health QOL, we may assume that they have found a way to cope with the loss of erection. However, we do not know whether patients were content with the loss or whether their partnered relationships accommodated this change without losing intimacy. Further measuring the sufficiency of erections for intercourse does not represent the complex nature of partnered sexuality. As little education is routinely offered to prostate cancer patients and partners on how to develop a new sexuality after treatment, couples may anticipate life without satisfactory sexual experiences, ${ }^{36}$ and resort to compensatory rather than effective coping. ${ }^{37}$ 


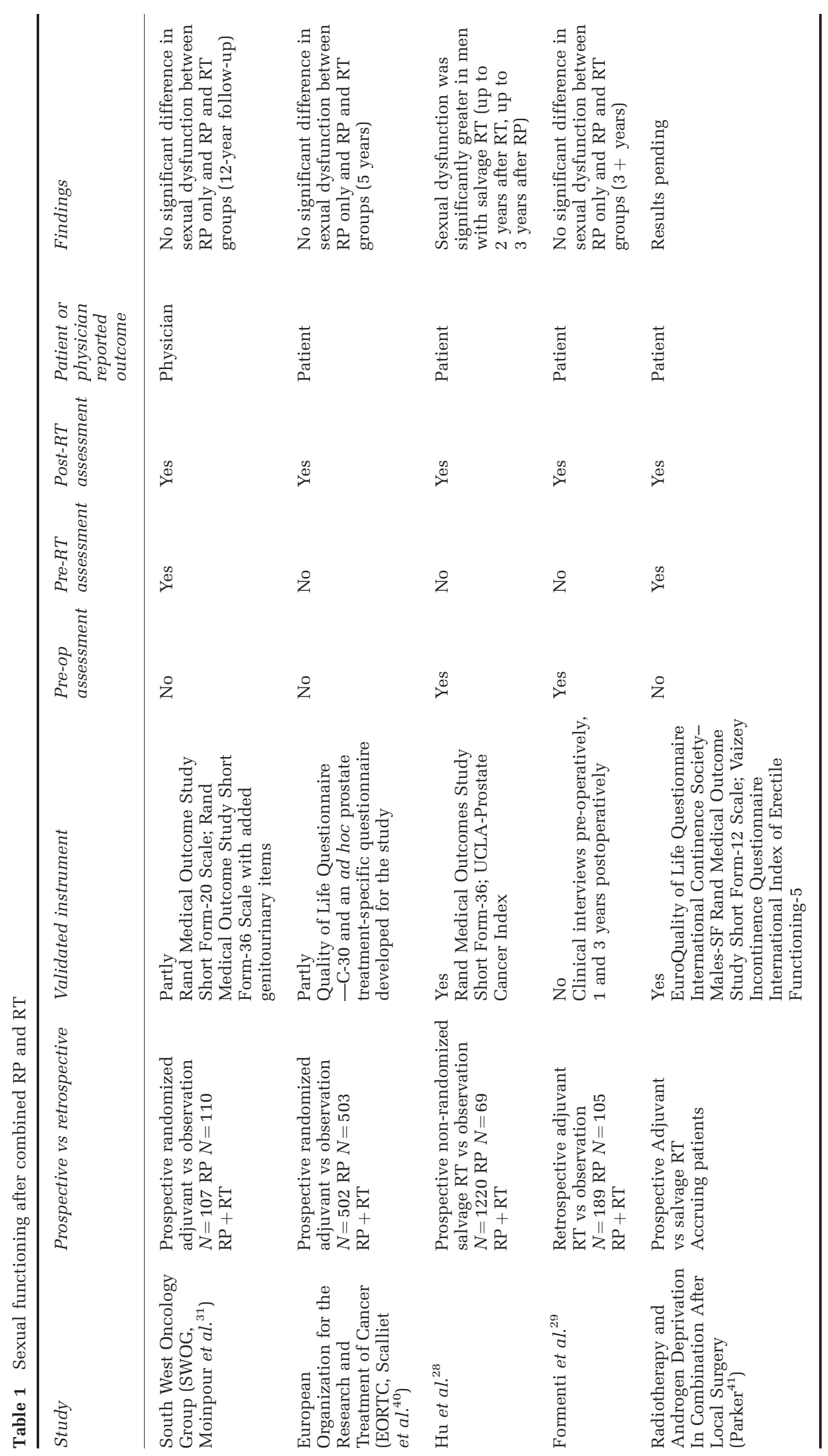


It is possible to explain the combined therapy group's more frequent report of an improved QOL over time by the difference in the use of salvage hormonal therapy between the two groups, which was not factored into the SWOG QOL study analysis; the rate of salvage hormonal therapy at 5 years was twice as high in the observation group as that in the combined therapy patients (21 vs $10 \%$, hazard ratio 0.45 (95\% confidence interval: $0.29-0.68$ ), $P<0.001$ ). This difference in hormonal therapy was maintained and increased over time. The lower use of salvage hormonal therapy in the combined modality group may have led to an overall better QOL-an association also shown in another study. ${ }^{23}$ Delay in the use of androgen ablation through adjuvant may result in a net improvement in sexual functioning. The impact of adjuvant or salvage hormonal therapy on erectile function merits further study.

The SWOG QOL analysis shows an increased urinary frequency in a proportion of men treated on the combined therapy arm as compared with the observation arm $(P=0.002)$, with a consistent increase of $15 \%$ in the proportion of patients reporting frequent urination. Urinary symptoms can be troubling to partners and can interfere with sexual interest, pleasure and partnered sexual activity. ${ }^{38}$ To evaluate the effects of combined therapy on sexual functioning, it would be necessary to conduct an in-depth assessment that would integrate body functions that affect sexuality and emotional responses to those by the man, partner and the couple. In addition, it is possible that efforts to enhance urinary rehabilitation may have a positive impact on sexual QOL in patients treated with surgery with or without radiation therapy.

Overall, methodological problems undermine the validity of the SWOG study's findings. The study does not include pre-prostatectomy erectile functioning assessment, which makes it difficult to know what sort of loss patients experienced from either surgery alone or from the combined treatment. We know that some men undergo prostate cancer treatment with already existing ED, ${ }^{23,39}$ which would presumably have an effect on their and their partners' adaptation. As the SWOG trial did not include this baseline assessment, long-term assessment will have limitations. Finally, as these were physician-reported outcomes and not all instruments were validated or sensitive to patients' feelings about their sexual dysfunction, these findings are of limited value.

The EORTC study provides limited data on sexual functioning after either surgery or combined treatment. A mixture of validated (QOL C-30) and nonvalidated (prostate treatment specific) questionnaires was used. However, assessment was carried out only once any time between 2 months and 7 years after treatment (average 2 years) without a follow-up of the evolution of side effects. ${ }^{40}$

The RADICALS study uses validated measures of QOL, including sexual functioning. ${ }^{41}$ Assessments begin postoperatively at randomization for radiation therapy, and are repeated 1, 5 and 10 years later. Unfortunately, preoperative sexual functioning will not be assessed, once again missing an opportunity to understand the change in sexual functioning that patients will face. In addition, surveys of QOL factors, although important in evaluating treatment toxicity, do not include patients' and couples' adaptation and hence need to be studied with a finer grain approach.

The evidence on the sexual side effects of combined therapy is uneven and sometimes contradictory. This is because of a number of factors: (1) measurement was not sufficiently developed when these studies began, thus making it impossible to make comparisons across studies; (2) combination therapy entailed varying dosages of radiation therapy and different timing of post-prostatectomy radiation; and (3) some patients may have received additional hormonal therapy in the process of the trial. The primary focus of these studies was on relapse and survival prevention, thus making the measurement of side effects more incidental. Since the 1990s, valid and reliable measures have been developed and can be used in prospective studies.

\section{Penile rehabilitation}

Penile rehabilitation has been developed in response to men's dissatisfaction with post-prostatectomy erectile difficulties. It also offers hope of recovering sexual intimacy to patients treated with combined therapy. Research on outcomes associated with nerve-sparing surgery suggests that nerve sparing leads to a more successful erectile recovery, ${ }^{42-45}$ including the preservation of penile length. ${ }^{46}$ Patients are usually advised that they will not know the extent of their recovery for up to 2 years. ${ }^{4}$ To maintain penile tissue health during the healing period, penile rehabilitation strategies have been developed and continue to be studied (Table 2). Some include daily low doses of phosphodiesterase type 5 (PDE-5) inhibitors or prostaglandin $\mathrm{E}$ to provide ongoing oxygenation of cavernosal tissues, and the use of vacuum evacuation devices to promote penile stretching so that presurgery penile size may be preserved. ${ }^{47-51}$ Khera $^{52}$ suggests in a literature review that post-prostatectomy testosterone replacement therapy (TRT) may be useful to patients who have problems with erections. $\mathrm{He}$ and colleagues ${ }^{53}$ report a retrospective review of their erectile preservation program. A total of 99 patients underwent a course of preoperative and postoperative nightly $25 \mathrm{mg}$ of sildenafil and $250 \mathrm{mcg}$ Medical Urethral System for Erection (MUSE) suppositories three times a week, with additional testosterone replacement therapy 1 month after surgery added for hypogonadal men with undetectable PSA and negative surgical margins. Female partners were included in the study and their sexual functioning was assessed pre- and 
Table 2 Aids to sexual recovery after post-prostatectomy radiation therapy (currently researched)

\begin{tabular}{l} 
Pharmacological \\
\hline $\begin{array}{l}\text { Penile rehabilitation options } \\
\text { (pretreatment) }\end{array}$ \\
Low-dose prostaglandin E \\
intracavernosal injections (5-10 mcg) or \\
transurethral suppositories (125-250 mcg) \\
periodically for 1 month or \\
Low-dose phosphodiesterase 5 inhibitors \\
(1/2 tab every other day) for 1 month
\end{tabular}

Penile rehabilitation options (posttreatment)

Low-dose prostaglandin E

intracavernosal injections $(5-10 \mathrm{mcg})$ or

transurethral suppositories (125-250 mcg)

every other day for 6 months or

Low-dose phosphodiesterase 5 inhibitors

(1/2 dose every other day) for 6 months

Testosterone replacement

Options of aids to erections

Prostaglandin E intracavernosal injections (5-20 mcg) or transurethral suppositories (125-1000 mcg)

Phosphodiesterase 5 inhibitors

$$
\text { Physical }
$$

Penile rehabilitation (pretreatment)

Kegel exercises (3 sets of 10) daily

Physical therapy for pelvic floor rehabilitation

Penile rehabilitation (posttreatment)

Kegel exercises (3 sets of 10) daily

Physical therapy for pelvic floor rehabilitation

Vacuum erectile devices (thrice a week) for 6 months

Self-stimulation/masturbation (daily) for 6 months

Options of aids to erections

Vacuum erectile devices

Vasoconstrictive rings
Psycho-sexual

Education (pretreatment)

Psychoeducation about the effect of prostate cancer treatment on sexual functioning

Psychoeducation about the typical emotional responses that men and partners experience in the aftermath of prostate cancer treatment (grief and mourning of old sexuality)

Interventions (posttreatment)

Comprehensive psychosexual assessment for the individual and couple

Psychoeducation about sexual recovery for the man and for the couple: sexual changes, feelings about them, need for experimentation as a part of developing new sexual relationship

Sex therapy when couple has concerns about resuming sexual relationship

Individual psychotherapy when man or partner is having difficulty adapting to new sexuality

Couple therapy when sexual issues are embedded in long-term couple difficulties

Support groups

Self-help books on sexuality after cancer treatment postoperatively. Pre- and postoperative female sexual functioning scores correlated significantly with those of men and were predictive of men's use of intracavernosal injections. Combination therapy was more effective than therapy with sildenafil alone. Moreover, testosterone replacement helped $68 \%$ of men achieve erection 9 months after surgery compared with $12 \%$ of men in the non-testosterone replacement therapy group. The value of early pelvic-floor biofeedback was also found to be effective in the rehabilitation process. ${ }^{54}$ Although this randomized trial was based on very small numbers of participants, the treatment group was able to show a better return to the ability to have intercourse than was the control group.

Initial evidence suggests that early penile rehabilitation leads to an increased chance of successful recovery of spontaneous erections. As the concept of penile rehabilitation has been developed and researched to help with the side effects of prostatectomy, its application to erectile recovery after radiation or combined treatment (either alone or after surgical therapy) and its effectiveness should be studied. Furthermore, research on aids to erectile functioning is extensive and offers hope to men whose ability to attain a spontaneous erection is compromised. Research on the use of penile injections, transurethral suppositories and vacuum erectile devices is ongoing, ${ }^{45,55-58}$ but men and partners need counseling and encouragement to take advantage of them.

Penile prostheses can be an ED treatment of choice for those men who do not benefit from oral, injectable or insertable medications, or for whom the desire for spontaneity remains an overriding factor after prostate cancer treatment. Urologists typically wait for 2 years before offering this option on the basis of the time it takes for nerve recovery when relevant, but patients can choose to pursue it earlier. Although men tend to be satisfied with the prosthesis, ${ }^{55,59}$ one study cautions that patients who are older and patients who undergo radical prostatectomy do not find it as satisfactory as does the general population. ${ }^{60}$ Careful counseling regarding expectations would be important as this is a treatment that is not reversible. 


\section{Helping patients make treatment decisions}

Given the evidence that adjuvant radiation therapy contributes positively to both biochemical control and survival of prostate cancer after radical prostatectomy with high-risk pathological features, a better understanding of the impact of adjuvant or salvage RT on sexuality is necessary. Radiation, adjuvant or salvage, may negatively affect erection, but if it prevents androgen ablation or disease recurrence, it may represent a best, if difficult treatment, choice. The balance between a desire for disease control (even if it does not prolong life) and potential negative effects on sexuality becomes complicated and requires sensitivity to patient priorities. In treatment choice discussions, providers can see their role not as advocates of a particular treatment but as guarantors of an opportunity for patients and partners to consider survival, the sexual side effects of treatment, and the signposts on a road map to sexual recovery. Not all providers may feel comfortable assuming a role in which survival and QOL concerns are discussed in the same breath. ${ }^{61}$ Research into patients' and partners' attitudes toward these choices would guide providers who wish to promote a fruitful decision-making process for patients and their partners.

A common assumption that survival overrides concern about QOL has not always been borne out in clinical practice because of concern that a life without quality is not worth living. ${ }^{62}$ This is of particular concern with clinically localized prostate cancer, wherein only a small proportion of patients are ever likely to die of disease, whereas all treated patients are subjected to risks of significant loss of sexual functioning. What factors are at play when the concern is not to end suffering, but to promote intimacy, pleasure and vitality in a couple's relationship? Research into this area will be helpful in the future, but there are some principles that can guide advising patients and partners even now.

Many physicians are aware that patient and partner-related factors are critical to sexual recovery. ${ }^{63}$ General research on patient decision making in prostate cancer care suggests that patients and their partners want to be informed and involved in making decisions with regard to their cancer treatment ${ }^{64-67}$ and treatment for sexual dysfunction. ${ }^{68}$ Provision of information may need to be individualized and different cultural groups may place different emphasis on sexual functioning. Awareness of such differences would be critical while providing counseling. ${ }^{69-72}$ This may not reliably occur at this time, particularly for gay men, ${ }^{73}$ African Americans ${ }^{70}$ and other ethnic groups. ${ }^{74}$

As the side effects of prostate cancer surgery are quite dramatic, uninformed patients would be more susceptible to regretting their treatment choice. Davison et al. ${ }^{64}$ studied treatment regret in prostate cancer and found that only a very small percentage of men ( $4 \%, N=140)$ regretted having decided on surgical treatment despite significant sexual side effects. However, Diefenbach et al. ${ }^{75}$ reported regret related to sexual bother and limitations because of urinary incontinence in the first year after treatment. It is not clear whether patients in those studies were fully informed before making decisions, but it is only human to regret a decision that leads to a disability. The studies reported here represent patient regret within the first year after treatment when uncertainty about the resolution of treatment side effects is at its peak.

Patients and partners for whom sexual intimacy is vital and for whom its loss would be devastating need to have an opportunity to evaluate (1) the risk for recurrence and related lifespan if they do not opt for adjuvant radiation, (2) thier likely response to the recurrence of disease, and (3) treatments and outcomes available in the salvage setting. Help anticipating treatment regret due to frustrations with side effects and their treatment could enable men and partners develop realistic expectations for physical functioning, as well as mitigate their emotional responses during the course of the first 2 years after treatment when side effects are resolving. According to Abelson et al. ${ }^{76}$ people who suffer from anxiety are less likely to develop symptoms when they are told to expect them.

Regardless of treatment choice, men can be counseled on a number of strategies for sexual recovery (Table 2). They can engage in penile rehabilitation so as to maintain optimal physical capacity for sexual recovery. In addition, all patients and partners would benefit from being counseled with regard to methods for maintaining intimacy, despite diminished erectile functioning. Initial research on intervention in the psycho-sexual aspects of recovery from prostate cancer treatment suggests that being informed and supported assists with coping. ${ }^{77-80}$ In a study by Titta et al., ${ }^{81}$ counseling successfully supported adherence to ED treatment after prostate cancer treatment. But sexual intimacy is not purely dependent on erection. ${ }^{82}$ The value and activities of nonpenetrative sexuality can be discussed with a certified sex therapist (approved by the American Association of Sexuality Educators, Counselors and Therapists). Exercises such as 'sensate focus', which were originally developed by Masters and Johnson, ${ }^{83}$ are typically taught in sex therapy to couples who wish to re-kindle or broaden their sexual repertoire. They are ideal for the vulnerable period of sexual recovery after prostate cancer. New ideas on how partnered sexual pleasure can be regained after sexual difficulties can be taught in sex therapy and found in self-help books that address sexual difficulties in a supportive and realistic way. ${ }^{84-86}$ With one notable exception, ${ }^{87}$ current available self-help literature focuses on heterosexual sexuality. We need self-help literature and evidence-based interventions focused on the 
sexual recovery of gay men and of men from a variety of ethnic groups so that their more specific needs can be met. Couples would benefit from being alerted to the emotional processing of sexual changes through the work of grief and mourning so that they can become emotionally ready to develop a new, diverse sexuality beyond penetrative sex. Healthcare providers are typically not easily able to discuss sexual issues, but methods for such conversations in prostate cancer care can be developed and promote comfort for both providers and patients. ${ }^{68}$ If patients feel that they can learn strategies for retaining sexual intimacy, they can maintain hope and actively pursue sexual recovery regardless of treatment choice.

\section{Summary}

Clinical trials that begin preoperatively, compare the timing of postoperative radiation, include prospective assessments of sexual functioning and couple functioning, and patients' and partners' concerns and wishes in this area are needed to help providers who counsel patients during prostate cancer treatment. In parallel, clinical trials of interventions that minimize the impact of postoperative radiation on sexuality, aid in treatment decision making and help couples maintain sexual intimacy are vital to this effort. Multidisciplinary prostate cancer care teams can maximize patients' overall life span and contribute to posttreatment QOL in the patient's intimate relationship.

\section{Conflict of interest}

Dave Wood - invested in Intuitive Surgical (makes da Vinci robots used for prostate cancer surgery).

\section{References}

1 Jemal A, Siegel R, Ward E, Ward E, Hao Y, Xu J et al. Cancer statistics, 2008. CA Cancer J Clin 2008; 58: 71-96.

2 Bill-Axelson A, Holmberg L, Ruutu M, Haggman M, Andersson SO, Bratell S et al. Radical prostatectomy versus watchful waiting in early prostate cancer. $N$ Engl J Med 2005; 352: 1977-1984.

3 Miller DC, Gruber SB, Hollenbeck BK, Montie JE, Wei JT. Incidence of initial local therapy among men with lower-risk prostate cancer in the United States. J Natl Cancer Inst 2006; 98: $1134-1141$.

4 Miller DC, Sanda MG, Dunn RL, Montie JE, Pimentel H, Sandler HM et al. Long-term outcomes among localized prostate cancer survivors: health-related quality-of-life changes after radical prostatectomy, external radiation, and brachytherapy. J Clin Oncol 2005; 23: 2772-2780.

5 Stephenson AJ, Shariat SF, Zelefsky MJ, Kattan MW, Butler EB, Teh BS et al. Salvage radiotherapy for recurrent prostate cancer after radical prostatectomy. JAMA 2004; 291: $1325-1332$
6 Stephenson AJ, Scardino PT, Kattan MW, Pisansky TM, Slawin KM, Klein EA et al. Predicting the outcome of salvage radiation therapy for recurrent prostate cancer after radical prostatectomy. J Clin Oncol 2007; 25: 2035-2041.

7 Vargas C, Kestin LL, Weed DW, Krauss D, Vicini FA, Martinez AA. Improved biochemical outcome with adjuvant radiotherapy after radical prostatectomy for prostate cancer with poor pathologic features. Int J Radiat Oncol Biol Phys 2005; 61: 714-724.

8 Wadasaki K, Kaneyasu Y, Kenjo M, Matsuura K, Murakami Y, Hashimoto $\mathrm{Y}$ et al. Treatment results of adjuvant radiotherapy and salvage radiotherapy after radical prostatectomy for prostate cancer. Int J Clin Oncol 2007; 12: 37-41.

9 Trabulsi EJ, Valicenti RK, Hanlon AL, Pisansky TM, Sandler HM, Kuban DA et al. A multi-institutional matched-control analysis of adjuvant and salvage postoperative radiation therapy for pT3-4No prostate cancer. Urology 2008; 72: 1298-1302, discussion 1302-1294.

10 Vicini FA, Ziaja EL, Kestin LL, Brabbins DS, Stromberg JS, Gonzalez JA et al. Treatment outcome with adjuvant and salvage irradiation after radical prostatectomy for prostate cancer. Urology 1999; 54: 111-117.

11 Thompson Jr IM, Tangen CM, Paradelo J, Lucia MS, Miller G, Troyer $\mathrm{D}$ et al. Adjuvant radiotherapy for pathologically advanced prostate cancer: a randomized clinical trial. JAMA 2006; 296: 2329-2335.

12 Kamat AM, Babaian K, Cheung MR, Naya Y, Huang SH, Kuban D et al. Identification of factors predicting response to adjuvant radiation therapy in patients with positive margins after radical prostatectomy. J Urol 2003; 170: 1860-1863.

13 Swanson GP, Goldman B, Tangen CM, Chin J, Messing E, Canby-Hagino $\mathrm{E}$ et al. The prognostic impact of seminal vesicle involvement found at prostatectomy and the effects of adjuvant radiation: data from Southwest Oncology Group 8794. J Urol 2008; 180: 2453-2457, discussion 2458.

14 Van der Kwast TH, Bolla M, Van Poppel H, van Cangh P, Vekemans K, Da Pozzo L et al. Identification of patients with prostate cancer who benefit from immediate postoperative radiotherapy: EORTC 22911. I Clin Oncol 2007; 25: 4178-4186.

15 Thompson IM, Tangen CM, Paradelo J, Lucia MS, Miller G, Troyer D et al. Adjuvant radiotherapy for pathological T3N0M0 prostate cancer significantly reduces risk of metastases and improves survival: long-term follow-up of a randomized clinical trial. J Urol 2009; 181: 956-962.

16 Bolla M, van Poppel H, Collette L, van Cangh P, Vekemans K, Da Pozzo L et al. Postoperative radiotherapy after radical prostatectomy: a randomised controlled trial (EORTC trial 22911). Lancet 2005; 366: 572-578.

17 Parker C. The case for selective salvage radiotherapy after radical prostatectomy. Proceedings of the 2009 Genitourinary Cancers Symposium of the American Society of Clinical Oncology 2009; 19-20.

18 Pollack A. Postoperative radiotherapy: data from clinical trials. Proceedings of the 2009 Genitourinary Cancers Symposium of the American Society of Clinical Oncology 2009; 15-16.

19 Wiegel T, Bottke D, Steiner U, Siegmann A, Golz R, Storkel S et al. Phase III postoperative adjuvant radiotherapy after radical prostatectomy compared with radical prostatectomy alone in pT3 prostate cancer with postoperative undetectable prostate-specific antigen: ARO 96-02/AUO AP 09/95. J Clin Oncol 2009; 27: 2924-2930.

20 Thompson IM, Tangen CM, Klein EA. Is there a standard of care for pathologic stage T3 prostate cancer? J Clin Oncol 2009.

21 Penson DF, McLerran D, Feng Z, Li L, Albertsen PC, Gilliland FD et al. 5-year urinary and sexual outcomes after radical prostatectomy: results from the Prostate Cancer Outcomes Study. J Urol 2008; 179: S40-S44.

22 Schover LR, Fouladi RT, Warneke CL, Neese L, Klein EA, Zippe C et al. Defining sexual outcomes after treatment for localized prostate carcinoma. Cancer 2002; 95: 1773-1785. 
23 Sanda MG, Dunn RL, Michalski J, Sandler HM, Northouse LL, Hembroff L et al. Quality of life and satisfaction with outcome among prostate-cancer survivors. $N$ Engl J Med 2008; 358: 1250-1261.

24 Beard CJ, Propert KJ, Rieker PP, Clark JA, Kaplan I, Kantoff PW et al. Complications after treatment with external-beam irradiation in early-stage prostate cancer patients: a prospective multiinstitutional outcomes study. J Clin Oncol 1997; 15: $223-229$.

25 Incrocci L. Radiation therapy for prostate cancer and erectile (dys)function: the role of imaging. Acta Oncol 2005; 44: 673-678.

26 van der Wielen GJ, Mulhall JP, Incrocci L. Erectile dysfunction after radiotherapy for prostate cancer and radiation dose to the penile structures: a critical review. Radiother Oncol 2007; 84: 107-113.

27 Incrocci L. Sexual function after external-beam radiotherapy for prostate cancer: what do we know? Crit Rev Oncol Hematol 2006; 57: 165-173.

$28 \mathrm{Hu}$ JC, Elkin EP, Krupski TL, Gore J, Litwin MS. The effect of postprostatectomy external beam radiotherapy on quality of life: results from the cancer of the prostate strategic urologic research endeavor. Cancer 2006; 107: 281-288.

29 Formenti SC, Lieskovsky G, Skinner D, Tsao-Wei DD, Groshen S, Petrovich Z. Update on impact of moderate dose of adjuvant radiation on urinary continence and sexual potency in prostate cancer patients treated with nerve-sparing prostatectomy. Urology 2000; 56: 453-458.

30 Valicenti RK, Gomella LG, Ismail M, Mulholland SG, Strup S, Petersen RO et al. Durable efficacy of early postoperative radiation therapy for high-risk pT3No prostate cancer: the importance of radiation dose. Urology 1998; 52: 1034-1040.

31 Moinpour CM, Hayden KA, Unger JM, Thompson IM, Redman MW, Canby-Hagin ED et al. Health-related quality of life results in pathologic stage $\mathrm{C}$ prostate cancer from a Southwest Oncology Group trial comparing radical prostatectomy alone with radical prostatectomy plus radiation therapy. J Clin Oncol 2008; 26: 112-120.

32 Wei JT, Dunn RL, Sandler HM, McLaughlin PW, Montie JE, Litwin MS et al. Comprehensive comparison of health-related quality of life after contemporary therapies for localized prostate cancer. J Clin Oncol 2002; 20: 557-566.

33 Hedestig O, Sandman PO, Tomic R, Widmark A. Living after radical prostatectomy for localized prostate cancer: a qualitative analysis of patient narratives. Acta Oncol 2005; 44: 679-686.

34 Bokhour BG, Clark JA, Inui TS, Silliman RA, Talcott JA. Sexuality after treatment for early prostate cancer: exploring the meanings of 'erectile dysfunction'. J Gen Intern Med 2001; 16: $649-655$.

35 Katz A. What happened? Sexual consequences of prostate cancer and its treatment. Can Fam Physician 2005; 51: 977-982.

36 Neese LE, Schover LR, Klein EA, Zippe C, Kupelian PA. Finding help for sexual problems after prostate cancer treatment: a phone survey of men's and women's perspectives. Psychooncology 2003; 12: 463-473.

37 Bokhour BG, Powel LL, Clark JA. No less a man: reconstructing identity after prostate cancer. Commun Med 2007; 4: 99-109.

38 Kornblith AB, Herr HW, Ofman US, Scher HI, Holland JC. Quality of life of patients with prostate cancer and their spouses. The value of a data base in clinical care. Cancer 1994; 73: 2791-2802

39 Walz J, Perrotte P, Suardi N, Hutterer G, Jeldres C, Bernard F et al. Baseline prevalence of erectile dysfunction in a prostate cancer screening population. J Sex Med 2008; 5: 428-435.

40 Scalliet PG, Remouchamps V, Curran D, Ledent G, Wambersie $\mathrm{A}$, Richard $\mathrm{F}$ et al. Retrospective analysis of results of $\mathrm{p}(65)+$ Be neutron therapy for treatment of prostate adenocarcinoma at the cyclotron of Louvain-la-Leuve. Part II: side effects and their influence on quality of life measured with
QLQ-C30 of EORTC. Int J Radiat Oncol Biol Phys 2004; 58: 1549-1561.

41 Parker C. Radiotherapy and androgen deprivation in combination after local surgery (RADICALS) study. Personal communication 2009

42 Dubbelman YD, Dohle GR, Schroder FH. Sexual function before and after radical retropubic prostatectomy: a systematic review of prognostic indicators for a successful outcome. Eur Urol 2006; 50: 711-718, discussion 718-720.

43 Michl U, Graefen M, Noldus J, Eggert T, Huland H. Functional results of various surgical techniques for radical prostatectomy. Urologe A 2003; 42: 1196-1202.

44 Michl UH, Friedrich MG, Graefen M, Haese A, Heinzer H, Huland $\mathrm{H}$. Prediction of postoperative sexual function after nerve sparing radical retropubic prostatectomy. J Urol 2006; 176: $227-231$.

45 Briganti A, Salonia A, Gallina A, Chun FK, Karakiewicz PI, Graefen $\mathrm{M}$ et al. Management of erectile dysfunction after radical prostatectomy in 2007. World J Urol 2007; 25: 143-148.

46 Briganti A, Fabbri F, Salonia A, Gallina A, Chun FK, Deho F et al. Preserved postoperative penile size correlates well with maintained erectile function after bilateral nerve-sparing radical retropubic prostatectomy. Eur Urol 2007; 52: 702-707.

47 Gontero P, Fontana F, Bagnasacco A, Panella M, Kocjancic E, Pretti $G$ et al. Is there an optimal time for intracavernous prostaglandin E1 rehabilitation following nonnerve sparing radical prostatectomy? Results from a hemodynamic prospective study. J Urol 2003; 169: 2166-2169.

48 Raina R, Pahlajani G, Agarwal A, Zippe CD. The early use of transurethral alprostadil after radical prostatectomy potentially facilitates an earlier return of erectile function and successful sexual activity. BJU Int 2007; 100: 1317-1321.

49 Mulhall JP, Morgentaler A. Penile rehabilitation should become the norm for radical prostatectomy patients. J Sex Med 2007; 4: 538-543.

50 Montorsi F, Guazzoni G, Strambi LF, Da Pozzo LF, Nava L, Barbieri L et al. Recovery of spontaneous erectile function after nerve-sparing radical retropubic prostatectomy with and without early intracavernous injections of alprostadil: results of a prospective, randomized trial. J Urol 1997; 158: 1408-1410.

51 Padma-Nathan H, McCullough AR, Levine LA, Lipshultz LI, Siegel R, Montorsi F et al. Randomized, double-blind, placebocontrolled study of postoperative nightly sildenafil citrate for the prevention of erectile dysfunction after bilateral nerve-sparing radical prostatectomy. Int J Impot Res 2008; 20: 479-486.

52 Khera M. Androgens and erectile function: a case for early androgen use in postprostatectomy hypogonadal men. J Sex Med 2009; 6: 234-238.

53 Khera M, Mohamed O, Colen JS, Link RE, Miles BJ, Lipshultz LI. Erectile preservation following radical prostatectomy: the Baylor experience. J Urol 2009; 181: 524.

54 Prota C, Riberio LS, Gomes CM, Bessa J, Poldarine MP, Nakano $\mathrm{E}$ et al. Early pelvic floor biofeedback training promotes improvement of erectile function after radical prostatectomy. J Urol 2009; 181: 524-525.

55 Stephenson RA, Mori M, Hsieh YC, Beer TM, Stanford JL, Gilliland FD et al. Treatment of erectile dysfunction following therapy for clinically localized prostate cancer: patient reported use and outcomes from the Surveillance, Epidemiology, and End Results Prostate Cancer Outcomes Study. J Urol 2005; 174: 646-650;, discussion 650.

56 Matthew AG, Goldman A, Trachtenberg J, Robinson J, Horsburgh S, Currie K et al. Sexual dysfunction after radical prostatectomy: prevalence, treatments, restricted use of treatments and distress. J Urol 2005; 174: 2105-2110.

57 Miller DC, Wei JT, Dunn RL, Montie JE, Pimentel H, Sandler $\mathrm{HM}$ et al. Use of medications or devices for erectile dysfunction among long-term prostate cancer treatment survivors: potential influence of sexual motivation and/or indifference. Urology 2006; 68: 166-171.

58 Schover LR, Fouladi RT, Warneke CL, Neese L, Klein EA, Zippe $\mathrm{C}$ et al. Seeking help for erectile dysfunction after 
treatment for prostate cancer. Arch Sex Behav 2004; 33 443-454.

59 Mulhall JP, Ahmed A, Branch J, Parker M. Serial assessment of efficacy and satisfaction profiles following penile prosthesis surgery. J Urol 2003; 169: 1429-1433.

60 Akin-Olugbade O, Parker M, Guhring P, Mulhall J. Determinants of patient satisfaction following penile prosthesis surgery. J Sex Med 2006; 3: 743-748.

$61 \mathrm{Yu}$ JS, Roach M. 3rd Quality of life and satisfaction with outcome among prostate-cancer survivors. N Engl J Med 2008; 359: 200, author reply 201-202.

62 Cochrane TI. Unnecessary time pressure in refusal of lifesustaining therapies: fear of missing the opportunity to die. Am J Bioeth 2009; 9: 47-54.

63 Lepor H, McCullough A, Engel JD. Renewing intimacy: advances in treating erectile dysfunction postprostatectomy. Rev Urol 2008; 10: 245-253.

64 Davison BJ, So AI, Goldenberg SL. Quality of life, sexual function and decisional regret at 1 year after surgical treatment for localized prostate cancer. BJU Int 2007; 100: 780-785.

65 Davison BJ, Goldenberg SL, Gleave ME, Degner LF. Provision of individualized information to men and their partners to facilitate treatment decision making in prostate cancer. Oncol Nurs Forum 2003; 30: 107-114.

66 Davison BJ, Gleave ME, Goldenberg SL, Degner LF, Hoffart D, Berkowitz J. Assessing information and decision preferences of men with prostate cancer and their partners. Cancer Nurs 2002; 25: 42-49.

67 Krist AH, Woolf SH, Johnson RE, Kerns JW. Patient education on prostate cancer screening and involvement in decision making. Ann Fam Med 2007; 5: 112-119.

68 Hartmann U, Burkart M. Erectile dysfunctions in patientphysician communication: optimized strategies for addressing sexual issues and the benefit of using a patient questionnaire. J Sex Med 2007; 4: 38-46.

69 Feldman-Stewart D, Brundage MD. Challenges for designing and implementing decision aids. Patient Educ Couns 2004, 54: 265-273.

70 Pierce R, Chadiha LA, Vargas A, Mosley M. Prostate cancer and psychosocial concerns in African American men: literature synthesis and recommendations. Health Soc Work 2003; 28: 302-311.

71 Maliski SL, Connor S, Fink A, Litwin MS. Information desired and acquired by men with prostate cancer: data from ethnic focus groups. Health Educ Behav 2006; 33: 393-409.

72 Namiki S, Kwan L, Kagawa-Singer M, Arai Y, Litwin MS. Sexual function following radical prostatectomy: a prospective longitudinal study of cultural differences between Japanese and American men. Prostate Cancer Prostatic Dis 2007; 11: 298-302.
73 Blank TO. Gay men and prostate cancer: invisible diversity. J Clin Oncol 2005; 23: 2593-2596.

74 Wittmann D, Northouse L, Foley S, Gilbert S, Wood D, Balon $\mathrm{R}$ et al. The psychosocial aspects of sexual recovery after prostate cancer treatment. Int J Impot Res 2009; 21: 99-106.

75 Diefenbach MA, Mohamed NE. Regret of treatment decision and its association with disease-specific quality of life following prostate cancer treatment. Cancer Invest 2007; 25: 449-457.

76 Abelson JL, Khan S, Liberzon I, Erickson TM, Young EA. Effects of perceived control and cognitive coping on endocrine stress responses to pharmacological activation. Biol Psychiatry 2008; 64: 701-707.

77 Manne S, Babb J, Pinover W, Horwitz E, Ebbert J. Psychoeducational group intervention for wives of men with prostate cancer. Psychooncology 2004; 13: 37-46.

78 Davison BJ, Elliott S, Ekland M, Griffin S, Wiens K. Development and evaluation of a prostate sexual rehabilitation clinic: a pilot project. BJU Int 2005; 96: 1360-1364.

79 Canada AL, Neese LE, Sui D, Schover LR. Pilot intervention to enhance sexual rehabilitation for couples after treatment for localized prostate carcinoma. Cancer 2005; 104: 2689-2700.

80 Molton IR, Siegel SD, Penedo FJ, Dahn JR, Kinsinger D, Traeger LN et al. Promoting recovery of sexual functioning after radical prostatectomy with group-based stress management: the role of interpersonal sensitivity. J Psychosom Res 2008; 64: 527-536.

81 Titta M, Tavolini IM, Moro FD, Cisternino A, Bassi P. Sexual counseling improved erectile rehabilitation after non-nervesparing radical retropubic prostatectomy or cystectomyresults of a randomized prospective study. J Sex Med 2006; 3: 267-273.

82 Wittmann D, Northouse L, Foley S, Gilbert S, Wood Jr DP, Balon $\mathrm{R}$ et al. The psychosocial aspects of sexual recovery after prostate cancer treatment. Int J Impot Res 2009; 21: 99-106.

83 Albaugh JA, Kellogg-Spadt S. Sensate focus and its role in treating sexual dysfunction. Urol Nurs 2002; 22: 402-403.

84 McCarthy B, McCarthy E. Discovering Your Couple Sexual Style. Taylor and Francis Group: NY, 2009.

85 McCarthy B, McCarthy E. Rekindling Desire: A step by step program to help low sex or no sex marriages. Brunner Rutledge: NY, 2003.

86 Metz M, McCarthy B. Coping with Erectile Dysfunction: How to regain confidence and enjoy great sex. New Harbinger Publications:Oakland CA, 2004.

87 Perlman G, Drescher J. A Gay Man's Guide to Prostate Cancer. The Haworth Medical Press Inc., 10 Alice Street, Binghamton, NY, 13904-1580 2005 . 